\title{
Polyphenols and triterpenes in leaves and extracts from three Nicotiana species
}

\author{
Venelina Popova ${ }^{1 *}$, Tanya Ivanova ${ }^{1}$, Albena Stoyanova ${ }^{1}$, Violeta Nikolova ${ }^{2}$, Tsveta Hristeva ${ }^{2}$, Margarita Docheva ${ }^{2}$, \\ Nikolay Nikolov ${ }^{2}$, Ivan Iliev ${ }^{1}$ \\ ${ }^{1}$ Department of Tobacco, Sugar, Vegetable and Essential Oils, University of Food Technologies, 4002 Plovdiv, Bulgaria, ${ }^{2}$ Tobacco and Tobacco Products Institute, \\ 4108 Markovo, Bulgaria
}

\section{ARTICLE INFO}

Article history:

Received on: December 13, 2018

Accepted on: February 02, 2019

Available online: September 10, 2019

\section{Key words:}

Polyphenols,

Triterpenes,

Tobacco,

Nicotiana,

Extracts

\section{ABSTRACT}

Genus Nicotiana (Solanaceae) includes 76 species, among which only Nicotiana tabacum L. (common tobacco) is recognized as economically important. Nicotiana species synthesize various secondary metabolites with biological or ecological activities, but many of them still have not been sufficiently studied. The objective of current study was to determine the content of selected groups of metabolites (e.g., phenolic acids, flavonoids, and triterpenes) in the leaves and extracts of three Nicotiana species (Nicotiana alata Link and Otto, Nicotiana rustica L., and N. tabacum L.), grown side by side. The results from the high-performance liquid chromatography identification of polyphenols and triterpenes in leaves and extracts showed considerable variations between the species. All of them, however, were characterized as plant materials containing various specialized and bioactive metabolites, which substantiate their consideration as a valuable source for obtaining different phytoproducts. In terms of the studied groups of bioactive metabolites, the results from the study suggest that $50 \%$ and $70 \%$ ethanol are the most suitable solvent concentrations for the extraction of $N$. alata, $N$. rustica, and $N$. tabacum leaves. The high content of polyphenols and triterpenes in the extracts provides grounds for their use in various cosmetic and pharmaceutical products, which could be the subject of future research.

\section{INTRODUCTION}

Genus Nicotiana (Solanaceae) includes 76 naturally occurring species, many of which have centuries-old history of use by the indigenous people of the Americas and Australia - for medicinal, religious, ornamental, pesticide, and various other purposes [1-4]. At present, Nicotiana species are distributed worldwide, but the only economically important among them are Nicotiana tabacum L. and to a lesser degree Nicotiana rustica L., which are cultivated for tobacco products intended for smoking, chewing, snuffing, etc. In a recent review by Jassbi et al. [3], Nicotiana genus is evaluated as "one of the most comprehensively studied flowering plant genera, with numerous studies having produced a large body of literature on its evolution, cytology, taxonomy, and biogeography" and "perhaps the most extensively studied genus at the genetic, genomic, and phenotypic levels." Species in the genus expose great morphological diversity, reasonably accompanied by a comprehensively documented chemical and functional diversity $[2,3,5]$.

The sectional classification of the Nicotiana species regarded in the current study according to Knapp et al. [2] is as follows: Nicotiana alata Link and Otto belongs to section Alatae (chromosome number $n=9$ ),

*Corresponding Author:

Venelina Popova,

Department of Tobacco, Sugar, Vegetable and Essential Oils,

University of Food Technologies, 26 Maritza Blvd., 4002 Plovdiv, Bulgaria.

Phone: +359-32-603-666.

E-mail: vpopova2000@abv.bg
N. rustica L. - to section Rusticae $(n=24)$, and N. tabacum L. - to section Nicotiana $(n=24)$.

$N$. alata is a perennial herbaceous plant, reaching a height of up to 40-70 cm, which native geographical distribution is in Uruguay, Brazil, and Argentina [2]. Leaves are relatively small (typically $<30 \mathrm{~cm}$ ), spatulate, sessile, with winged petioles. One of the most distinctive features of the species (also referred to as "jasmine tobacco" or "flowering tobacco") is its beautiful, abundant, and scented flowers, due to which $N$. alata, nowadays, is grown worldwide as an ornamental plant, found in many varieties and hybrids with varying floral characteristics $[2,6]$. The flowers of $N$. alata are relatively more studied than the leaves, and scientific evidence about the chemical constituents (besides nicotine) of the leaves is hardly available.

$N$. rustica is an annual herbaceous plant, which grows from $0.6 \mathrm{~m}$ to $1.5 \mathrm{~m}$ tall, with broad, ovate, and petiolate leaves [1,2]. The species is native to the Andean region and has been historically used as a sacred plant in religious ceremonies and as a medicine by the American Indians $[4,7]$. Nowadays, $N$. rustica is naturalized worldwide, being cultivated for smoking, chewing, or snuff tobacco products $[4,8,9]$. Unlike $N$. alata, $N$. rustica leaves carry high concentrations of nicotine and are considered useful for obtaining biopesticides [9-11].

N. tabacum L. (common tobacco, cultivated tobacco, or simply: Tobacco) is an herbaceous annual or perennial plant, which is one of the most commercially important technical crops around the world [3]. The species has been developed into numerous cultivars, varieties, and commercial types, representing an enormous diversity in plant 
habitus, leaf shape, size, yield, chemical, or smoking properties, etc. $N$. tabacum is one of the most thoroughly studied plant species, with $>2500$ metabolites identified in the leaves $[3,5,12]$.

Although many Nicotiana species - inclusive of N. alata, N. rustica, and $N$. tabacum are considered as traditionally intended for smoking [4], they all are capable of intensive biosynthesis of secondary (or specialized) metabolites with various biological or ecological activities. The metabolites (including alkaloids, terpenoids, phenolics, flavonoids, isoprenoids, and many other classes of chemicals) isolated from leaves, flowers or other plant organs inspire innovative, much broader application by people of the species of Nicotiana genus $[3,5,12]$.

Therefore, the objective of current study was to characterize selected groups of metabolites (phenolic acids [PAs], flavonoids, and triterpenes) in the leaves and ethanol extracts of three Nicotiana species (N. alata, N. rustica, and N. tabacum) grown side by side.

\section{MATERIALS AND METHODS}

\subsection{Plant Material}

The study was carried out with cured leaves of three Nicotiana species - N. alata, N. rustica, and N. tabacum. The latter of the species was represented by a local variety named "Plovdiv 7" belonging to the Basma variety group of Oriental (also known as aromatic or Turkish) tobacco. The species were grown side by side, in the region of Plovdiv, South Bulgaria, crop year 2017. Leaves were picked at maturity, suncured following the established technology, and stored until processing at a temperature of $5-8^{\circ} \mathrm{C}$ to avoid undesirable changes.

The moisture content of the plant materials was determined by drying to constant weight at a temperature of $105^{\circ} \mathrm{C}$ [13]. Before phytochemical analyses, the samples were dried at $40^{\circ} \mathrm{C}$ for $6 \mathrm{~h}$, ground in a laboratory mill, and then finely powdered by a laboratory homogenizer.

\subsection{Determination of Polyphenols}

Triple extraction of $0.5 \mathrm{~g}$ finely powdered tobacco with $70 \%$ methanol (Sigma-Aldrich, St. Louis, MO, USA) was carried out, each at $70^{\circ} \mathrm{C}$ for $3 \mathrm{~h}$ in an ultrasonic bath. The combined extract was evaporated at $60^{\circ} \mathrm{C}$ on a rotary evaporator, and the residue was dissolved in methanol (Sigma-Aldrich, St. Louis, MO, USA). The obtained methanol solution was adjusted to $5 \mathrm{~mL}$ in a volumetric flask (IsoLab, Germany), and filtered before injection through a $0.45 \mu \mathrm{m}$ syringe filter (Chromafil Xtra PTFE-45/25, Macherey-Nagel, Germany) [14].

\subsubsection{High-performance liquid chromatography (HPLC) analysis of $P A s$}

Analysis of PAs was carried out on a Waters 1525 Binary Pump HPLC system (Waters, Milford, MA, USA), equipped with Waters 2487 Dual $\lambda$ Absorbance detector. The separation of PAs was on a SUPELCO Discovery HS C18 column $(5 \mu \mathrm{m}, 250 \mathrm{~mm} \times 4.6 \mathrm{~mm})$, operated at a temperature of $26^{\circ} \mathrm{C}$, at detection wavelengths of $280 \mathrm{~nm}$ and $320 \mathrm{~nm}$, and with mobile phases $2 \%$ acetic acid, v/v (Solvent A) and $0.5 \%$ acetic acid: acetonitrile $(1: 1, \mathrm{v} / \mathrm{v})$ (Solvent B). The elution gradient was according to Marchev et al. [15]: 0-30 min - Solvent B increased from $5 \%$ to $35 \%$ at a flow rate of $0.8 \mathrm{~mL} / \mathrm{min} ; 30-45 \mathrm{~min}-$ from $35 \%$ to $70 \%(0.4 \mathrm{~mL} / \mathrm{min}) ; 45-50 \mathrm{~min} \mathrm{-} \mathrm{from} 70 \%$ to $80 \%$ (1.2 $\mathrm{mL} / \mathrm{min})$; $50-60 \mathrm{~min}$ - from $80 \%$ to $100 \%(1.2 \mathrm{~mL} / \mathrm{min})$; and 60-65 min - dropped down from $100 \%$ to $5 \%$ (at $0.8 \mathrm{~mL} / \mathrm{min}$ ), and then maintained to $70 \mathrm{~min}$ for column equilibration. The determination of PAs was done by building calibration curves, with rosmarinic, gallic, protocatechuic, salicylic, chlorogenic, vanillic, caffeic, syringic, ferulic, sinapic, $p$-coumaric, and cinnamic acids used as standards (all purchased from Sigma-Aldrich, St. Louis, MO, USA).

\subsubsection{HPLC analyses of flavonoids}

Column and HPLC system were the same as in the PA analysis. The mobile phases in the gradient elution were $2 \%$ acetic acid, $\mathrm{v} / \mathrm{v}$ (Solvent A) and methanol (Solvent B), and gradient setup was as follows: $0-10 \mathrm{~min}$ - Solvent B increased from $30 \%$ to $50 \%$ at a flow rate of $1.0 \mathrm{~mL} / \mathrm{min} ; 10-15 \mathrm{~min}$ - maintained; $15-16 \mathrm{~min}$ - increased to $52 \%$ (at $0.8 \mathrm{~mL} / \mathrm{min}$ ); $16-30 \mathrm{~min}$ - from $52 \%$ to $80 \%(0.8 \mathrm{~mL} / \mathrm{min})$; and 30-35 $\mathrm{min}$ - reduced to $30 \%(1.0 \mathrm{~mL} / \mathrm{min})$, and then maintained to $40 \mathrm{~min}$ to equilibrate the column [15]. The detection of flavonoids was carried out at 308 and $380 \mathrm{~nm}$, and the standards used to build the calibration curves were myricetin, kaempferol, quercetin, hesperidin, and apigenin (Sigma-Aldrich, St. Louis, MO, USA).

\subsubsection{HPLC analyses of flavonoid glycosides}

The quercetin glycosides rutin and hyperosid were analyzed on the same HPLC system and column, with mobile phases $2 \%$ acetic acid, $\mathrm{v} / \mathrm{v}$ (Solvent A) and acetonitrile (Solvent B), and detection wavelength $370 \mathrm{~nm}$, and the following elution gradient: $0-15 \mathrm{~min}-20 \%$ Solvent B; 15-17 min - 50\% Solvent B; and 17-20 min - 20\% Solvent B [16]. Calibration curves were built using rutin and hyperosid standards (Sigma-Aldrich, St. Louis, MO, USA).

\subsection{HPLC Analysis of Triterpenes}

About $1.0 \mathrm{~g}$ of homogenized tobacco were subjected to triple ultrasound-assisted extraction with acetone, each for $30 \mathrm{~min}$ at a temperature of $45^{\circ} \mathrm{C}$ and a hydro module of $1: 20(\mathrm{w} / \mathrm{v})$. The combined extract was evaporated at $60^{\circ} \mathrm{C}$ on a rotary vacuum evaporator, and then the residue was transferred to $1 \mathrm{~mL}$ of methanol [14].

The same HPLC unit as that described in section 2.2.1 was used for the analysis of triterpenes, with the mobile phase being a methanol:0.01M potassium dihydrogen phosphate $(\mathrm{pH} 2.8)=88: 12$ solution $(\mathrm{v} / \mathrm{v})$, and the flow rate gradient set up as follows: $0-18 \mathrm{~min}-$ at $0.8 \mathrm{~mL} / \mathrm{min}$; $18-19 \mathrm{~min}$ - at $0.6 \mathrm{~mL} / \mathrm{min} ; 19-30 \mathrm{~min}$ - at $0.6 \mathrm{~mL} / \mathrm{min} ; 30-31 \mathrm{~min}$ - at $0.8 \mathrm{~mL} / \mathrm{min}$, and $31-40 \mathrm{~min}$ - at $0.8 \mathrm{~mL} / \mathrm{min}$. Detection was carried out at $210 \mathrm{~nm}$, and quantification - against a calibration curve, with betulin, betulinic, carnosic, ursolic, and oleanolic acids (97\%) (Extrasynthese, France) used as standards [15].

\subsection{Obtaining of Nicotiana Leaf Extracts}

Before processing dried leaves were cut and fractionated to obtain uniform samples with a particle size of about $10 \times 15 \mathrm{~mm}$. The extraction was carried out under the following technological parameters: Raw material: solvent - 1:10 (w/v), solvent - ethanol in four concentrations $(30,50,70$, and $95 \%, v / v)$, duration - $5 \mathrm{~h}$, and temperature $-60^{\circ} \mathrm{C}$. Extraction conditions were selected according to the previous data from process modeling [17], which defined the applied combination of temperature and duration as the optimal in terms of tannin yield in the extracts from the studied Nicotiana species. Ethanol in different concentrations is recognized as the most popular polar solvent for obtaining biologically active extracts from medicinal and aromatic plants intended for food, cosmetic, and other purposes $[13,18,19]$, as well as for processing tobacco leaves $[17,19,20]$.

\section{RESULTS AND DISCUSSION}

\subsection{Results}

The moisture content of the analyzed plant materials was as follows: N. alata $-10.17 \%$, N. rustica $-9.17 \%$, and N. tabacum $-7.84 \%$. 
Data about the content of polyphenols and triterpenes in the leaves of the three studied Nicotiana species are presented in Table 1, and data from the analysis of the respective ethanol extracts are presented in Table 2.

The obtained results undoubtedly revealed that all Nicotiana species in the study contained significant amounts of the selected groups of metabolites (PAs, flavonoids, flavonoid glycosides, and triterpenes), which were, in turn, transferred into the obtained extracts. At the same time, there were observed considerable numerical and compositional variations in polyphenol and triterpene distribution between the species, concerning both the leaves and the ethanol extracts.

\subsection{DISCUSSION}

\subsubsection{N. alata}

Analytical data revealed that the group of PAs in the leaves of $N$. alata was dominated by caffeic $(1202.60 \mu \mathrm{g} / \mathrm{g})$ and chlorogenic $(974.12 \mu \mathrm{g} / \mathrm{g})$ acids, that of flavonoids - by myricetin $(48.73 \mu \mathrm{g} / \mathrm{g})$, the flavonoid glycosides - by rutin $(441.37 \mu \mathrm{g} / \mathrm{g})$, and the triterpenes - by

Table 1: Polyphenols and triterpenes $(\mu \mathrm{g} / \mathrm{g} D W)$ in the leaves of three Nicotiana species

\begin{tabular}{|c|c|c|c|}
\hline Compound & $\mathbf{N A}^{1}$ & $\mathbf{N R}^{2}$ & $\mathbf{N T}^{3}$ \\
\hline \multicolumn{4}{|l|}{ Phenolic acids } \\
\hline Gallic acid & $53.52 \pm 0.48^{4}$ & $42.12 \pm 0.22$ & $90.75 \pm 0.67$ \\
\hline Protocatechuic acid & $41.81 \pm 0.41$ & $795.26 \pm 5.52$ & $1334.94 \pm 8.47$ \\
\hline Salicylic acid & $299.94 \pm 1.28$ & $239.85 \pm 1.36$ & $403.09 \pm 1.62$ \\
\hline Chlorogenic acid & $974.12 \pm 7.46$ & $1100.71 \pm 7.88$ & $2377.07 \pm 7.88$ \\
\hline Vanillic acid & $664.25 \pm 5.47$ & $163.90 \pm 1.02$ & $225.70 \pm 1.44$ \\
\hline Caffeic acid & $1202.60 \pm 8.63$ & $306.61 \pm 2.07$ & $396.50 \pm 1.53$ \\
\hline Syringic acid & $275.93 \pm 2.14$ & $300.30 \pm 1.65$ & $263.93 \pm 1.43$ \\
\hline p-Coumaric acid & $110.85 \pm 1.03$ & $1362.75 \pm 8.41$ & $173.25 \pm 1.11$ \\
\hline Sinapic acid & $303.35 \pm 1.28$ & $1162.60 \pm 7.99$ & $3666.37 \pm 9.54$ \\
\hline Ferulic acid & $622.02 \pm 5.48$ & $536.24 \pm 4.25$ & $288.07 \pm 1.04$ \\
\hline Cinnamic acid & $30.90 \pm 0.27$ & $16.21 \pm 0.21$ & $48.24 \pm 0.51$ \\
\hline Rosmarinic acid & $443.12 \pm 2.98$ & $2404.19 \pm 9.33$ & $2103.41 \pm 8.57$ \\
\hline \multicolumn{4}{|l|}{ Flavonoids } \\
\hline Myricetin & $48.73 \pm 0.33$ & $80.08 \pm 0.42$ & $107.76 \pm 1.08$ \\
\hline Hesperetin & $\mathrm{nd}^{5}$ & nd & nd \\
\hline Quercetin & $10.85 \pm 0.09$ & $24.57 \pm 0.11$ & $20.13 \pm 0.13$ \\
\hline Luteolin & $9.07 \pm 0.08$ & $70.70 \pm 0.32$ & $96.00 \pm 0.41$ \\
\hline Kaempferol & $10.70 \pm 0.09$ & $22.86 \pm 0.18$ & $19.99 \pm 0.11$ \\
\hline Apigenin & $5.37 \pm 0.02$ & $48.95 \pm 0.31$ & $319.96 \pm 2.08$ \\
\hline \multicolumn{4}{|l|}{ Flavonoid glycosides } \\
\hline Rutin & $441.37 \pm 3.02$ & $4324.88 \pm 9.31$ & $8030.36 \pm 9.77$ \\
\hline Hyperoside & nd & $210.07 \pm 2.06$ & $40.44 \pm 0.28$ \\
\hline \multicolumn{4}{|l|}{ Triterpenes } \\
\hline Carnosic acid & $\operatorname{tr}^{6}$ & $87.62 \pm 0.75$ & $\operatorname{tr}$ \\
\hline Betulin & $216.63 \pm 2.01$ & $22.27 \pm 0.14$ & $51.41 \pm 0.24$ \\
\hline Betulinic acid & $84.66 \pm 0.76$ & $61.06 \pm 0.37$ & $\operatorname{tr}$ \\
\hline Oleanolic acid & $\operatorname{tr}$ & $78.31 \pm 0.34$ & $5.54 \pm 0.01$ \\
\hline Ursolic acid & nd & $67.34 \pm 0.23$ & $16.71 \pm 0.18$ \\
\hline
\end{tabular}

${ }^{1} \mathrm{NA}: N$. alata Link\&Otto, ${ }^{2} \mathrm{NR}:$ N. rustica L., ${ }^{3} \mathrm{NT}$ : $N$. tabacum L. (Oriental type, variety "Plodviv 7"), ${ }^{4} \mathrm{Mean} \pm \mathrm{SD}(n=3),{ }^{5}$ tr: Trace amount, ${ }^{6}$ nd: Not detected betulin $(216.63 \mu \mathrm{g} / \mathrm{g})$. Ursolic acid was not detected in $N$. alata leaves, while carnosic and oleanolic acids were found only in trace amounts. There were numerical differences from data reported in previous studies on $N$. alata leaf composition [6], which could be explained by the influence of crop year, environmental, and other factors. The concentrations of the individual groups of polyphenol compounds varied considerably in the four ethanol extracts, as well, which are explicable by the different selectivity of the solvent. In terms of PAs, the highest concentration in the extract obtained with $30 \%$ ethanol was found for sinapic and chlorogenic acids; in that with $50 \%$ ethanol - for chlorogenic, syringic and sinapic acids; in the extract with $70 \%$ ethanol - for chlorogenic, caffeic and vanillic acids, and in the extract with $95 \%$ ethanol - for syringic acid. The group of flavonoids in the extract obtained with $30 \%$ ethanol from $N$. alata leaves was dominated by apigenin and luteolin, with $50 \%$ ethanol - by hesperetin, with $70 \%$ ethanol - by myricetin, and with $95 \%$ ethanol - by apigenin and myricetin. Among the flavonoid glycosides, hyperosid was not identified in the extracts, and rutin concentration was highest in the extract obtained with 50\% ethanol. The extraction of triterpenes from $N$. alata leaves was also strongly influenced by the solvent, with the highest concentration of triterpenes being registered in the extract obtained with $70 \%$ ethanol - betulin $(121.22 \mu \mathrm{g} / \mathrm{mL})$, oleanolic acid $(107.18 \mu \mathrm{g} / \mathrm{mL})$, and betulinic acid $(82.82 \mu \mathrm{g} / \mathrm{mL})$, respectively. Ursolic acid was not identified in either of the extracts, while in the extract with $30 \%$ ethanol no triterpenes was detected at all.

\subsubsection{N. rustica}

With regard to $N$. rustica leaves, the most abundant free PAs were rosmarinic, $p$-coumaric, sinapic, and chlorogenic acids (the respective levels being within the range from 2404.19 to $1100.71 \mu \mathrm{g} / \mathrm{g}$ ). The group of flavonoids was dominated by myricetin and luteolin $(80.08$ and $70.70 \mu \mathrm{g} / \mathrm{g}$, respectively) and that of flavonoid glycosides - by rutin $(4324.88 \mu \mathrm{g} / \mathrm{g})$. Five triterpenes were identified in the leaves, and the highest amounts were those of carnosic $(87.62 \mu \mathrm{g} / \mathrm{g})$ and oleanolic $(78.31 \mu \mathrm{g} / \mathrm{g})$ acids. In the ethanol extracts, the levels of the identified compounds varied substantially by solvent concentration, due to the impact of solvent selectivity on the transfer of the soluble polyphenols and triterpenes. In terms of PAs, the extract obtained with $30 \%$ ethanol had the highest concentration of salicylic, ferulic, and rosmarinic acids; with $50 \%$ ethanol - of rosmarinic, sinapic and protocatechuic acids; with $70 \%$ ethanol - of rosmarinic and chlorogenic acids, and the extract with $95 \%$ ethanol - of rosmarinic and sinapic acids. Within the flavonoid group, the extract with $30 \%$ ethanol had the highest concentration of luteolin and myricetin, those with $50 \%$ and $70 \%$ ethanol - of apigenin and luteolin, and that with 95\% ethanol - of myricetin and luteolin. All extracts contained high levels of the flavonoid glycoside rutin (varying from 232.92 to $395.19 \mu \mathrm{g} / \mathrm{mL}$ ), while hyperoside was identified only in the extracts obtained with $50 \%$ and $70 \%$ ethanol. The highest concentration of triterpenes was found in the extract obtained with $50 \%$ ethanol - betulinic acid $(59.49 \mu \mathrm{g} / \mathrm{mL})$ and betulin $(25.18 \mu \mathrm{g} / \mathrm{mL})$, while no triterpenes were detected in the extract with $30 \%$ ethanol.

\subsubsection{N. tabacum}

Data in Table 1 about the leaves of common tobacco ( $N$. tabacum) revealed that in the group of PAs the highest were the amounts of sinapic, chlorogenic, and rosmarinic acids (3666.37, 2377.07, and $2103.41 \mu \mathrm{g} / \mathrm{g}$, respectively); in the group of flavonoids - of apigenin $(319.96 \mu \mathrm{g} / \mathrm{g}$ ) and myricetin $(107.76 \mu \mathrm{g} / \mathrm{g})$, and in the group of flavonoid glycosides - of rutin (being reasonably the highest among the studied species $-8030.36 \mu \mathrm{g} / \mathrm{g}$ ). Again, as it was the case with $N$. alata leaf composition, there were numerical differences on polyphenol and 
$\bar{z}$

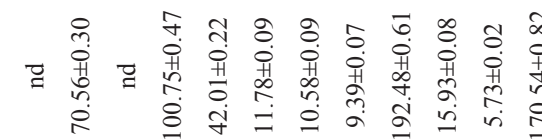

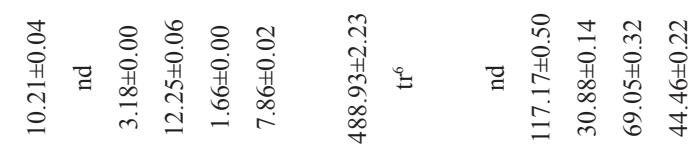

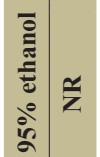

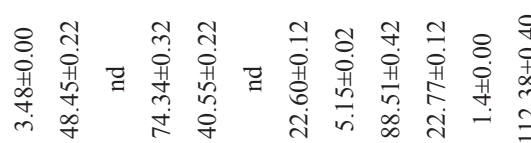

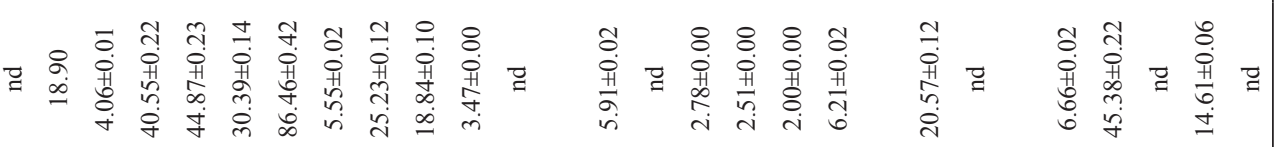
ธ กิ

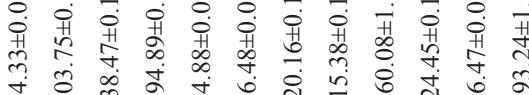

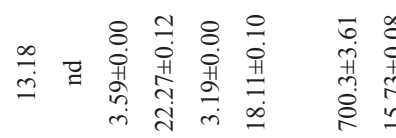

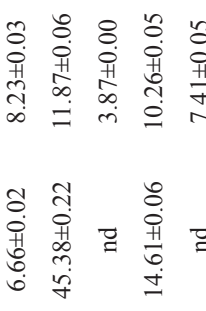

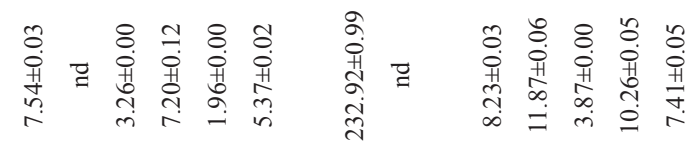

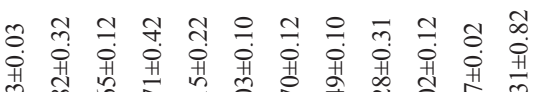
त̂ำ

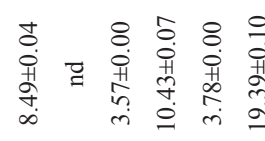

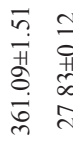

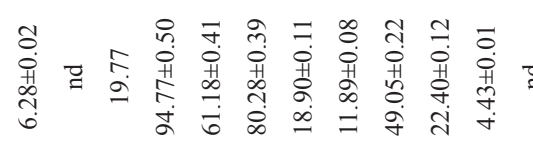

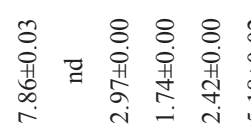
0
$\ddot{1}$
0
01
0
0
$m$
$m$ 8.

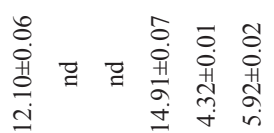

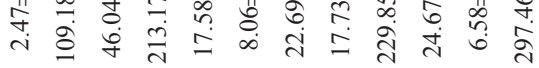

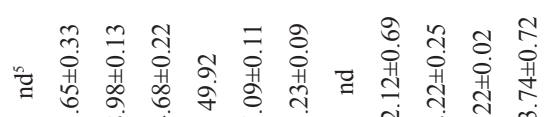

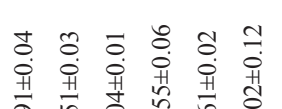
लंख्यों

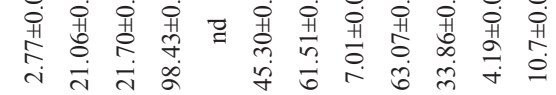

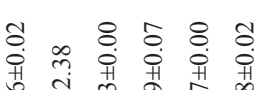

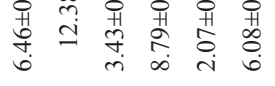

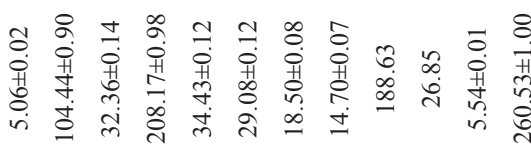

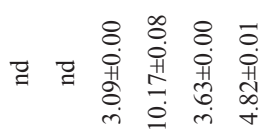

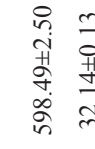

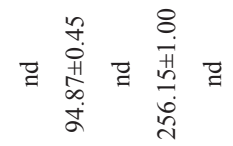
\& 8 \& $\stackrel{\circ}{\circ} \stackrel{\circ}{\circ} \div$

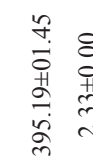

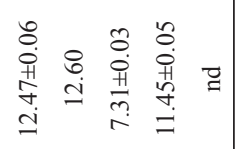
कू

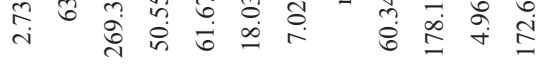

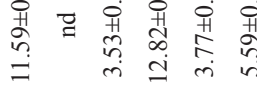
ปั.

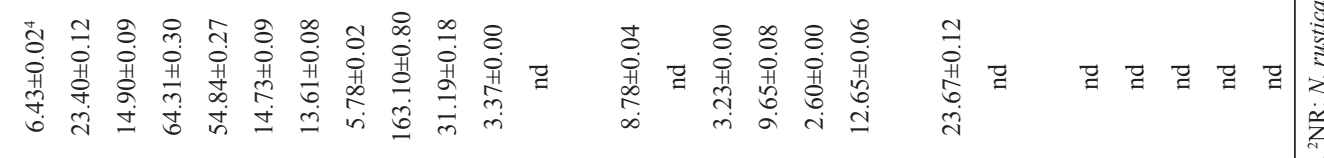

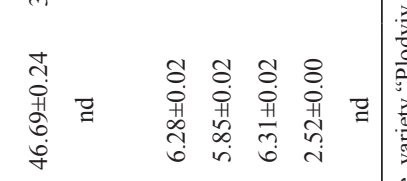

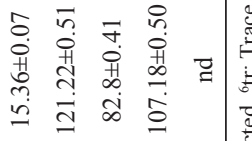


triterpene basis from previous studies on the same tobacco variety [21], explainable by crop year and other influencing factors. Similar to the observations about the leaf extracts from $N$. alata and N. rustica, the four ethanol extracts from $N$. tabacum leaves [Table 2] differed by polyphenol and triterpene concentration. The distribution of the major representatives within the respective group of metabolites in the extracts was as follows: PAs - the highest content in all extracts was that of rosmarinic, sinapic, and chlorogenic acids; flavonoids - the content of luteolin was the highest in all extracts; flavonoid glycosides - all extracts contained high levels of rutin; and triterpenes - the extracts with $70 \%$ and $95 \%$ ethanol were with the highest concentration of oleanolic acid and betulin.

\section{CONCLUSIONS}

The comparative analysis of the results about the content of the studied groups of bioactive metabolites (polyphenols and triterpenes) in the leaves and extracts of the three Nicotiana species suggests that:

- All Nicotiana species represent a plant material containing various metabolites capable of biological activities (PAs, flavonoids, flavonoid glycosides, and triterpenes), which substantiate their consideration as a valuable source for obtaining different phytoproducts.

- Ethanol in a 95\% concentration is not a suitable solvent for the leaves of the studied Nicotiana species.

- Ethanol in a $30 \%$ concentration can be considered for use only in the extraction of $N$. rustica leaves.

- $50 \%$ ethanol is the most suitable solvent for the extraction of N. alata leaves, while $70 \%$ ethanol - for the leaves of $N$. tabacum.

- The high content of polyphenols and triterpenes in the extracts provide grounds for their use in various cosmetic and pharmaceutical products, which could be the subject of future research.

\section{ACKNOWLEDGMENT}

The authors acknowledge the support by the Science Fund of the University of Food Technologies, Plovdiv (Project No 04/18-N). The authors are sincerely thankful to the anonymous reviewers for their help in improving this paper.

\section{REFERENCES}

1. Yadav R, Rathi M, Pednekar A, Rewachandani Y. Detailed review on solanaceae family. Eur J Pharm Med Res 2016;3:369-78.

2. Knapp S, Chase MW, Clarkson JJ. Nomenclatural changes and a new sectional classification in Nicotiana (Solanaceae). Taxon 2004;53:73-82.

3. Jassbi AR, Zare S, Asadollahi M, Schuman MC. Ecological roles and biological activities of specialized metabolites from the genus Nicotiana. Chem Rev 2017;117:12227-80.

4. Kishore K. Monograph of tobacco (Nicotiana tabacum). Indian J Drugs 2014;2:5-23.

5. Rodgman A, Perfetti T, editors. The Chemical Components of Tobacco and Tobacco Smoke. $2^{\text {nd }}$ ed. Boca Raton, Florida: CRC Press; 2013.
6. Popova V, Ivanova T, Nikolova V, Stoyanova A, Docheva M, Hristeva $\mathrm{T}$, et al. Biologically active and volatile compounds in leaves and extracts of Nicotiana alata Link and Otto from Bulgaria. J Pharm Sci Res 2017;9:2045-51.

7. Winter JC, editor. Tobacco Use by Native North Americans: Sacred Smoke and Silent Killer. Norman, USA: University of Oklahoma Press; 2000.

8. Djordjevic MV, Doran KA. Nicotine content and delivery among tobacco products. In: Henningfield JE, London ED, Pogun S, editors. Nicotine Psychopharmacology. Handbook of Experimental Pharmacology. Vol. 192. Berlin Heidelberg: Springer-Verlag; 2009. p. 61-82.

9. Kurucu S, Kartal M, Erenmemisoglu A. HPLC analysis of Nicotiana rustica L. and chewing tobacco (Maras powder) alkaloids. FABAD J Pharm Sci 1998;23:61-4.

10. Saitoh F, Noma M, Kawashima N. The alkaloid contents of sixty Nicotiana species. Phytochemistry 1985;24:477-80.

11. Sisson VA, Severson RF. Alkaloid composition of the Nicotiana species. Beitr Tabakforsch Int 1990;14:327-99.

12. Leffingwell J. Basic chemical constituents of tobacco leaf and differences among tobacco types. In: Davis D, Nielsen M, editors. Tobacco: Production, Chemistry and Technology. London: Blackwell Science; 1999. p. 265-84.

13. Pharmacopoeia Committee, Ministry of Health of the USSR. State Pharmacopoeia of the USSR. 11th ed., part 2. Moscow: Medicina; 1990.

14. Marchev A. Biologically Active Substances from Rare Bulgarian Salvia Species and their in vitro Cultures. PhD Dissertation. Sofia: Institute of Microbiology; 2014.

15. Marchev A, Georgiev V, Ivanov I, Badjakov I, Pavlov A. Two-phase temporary immersion system for agrobacterium rhizogenes genetic transformation of sage (Salvia tomentosa mill.). Biotechnol Lett 2011;33:1873-8.

16. Ivanov I, Vrancheva R, Marchev A, Petkova N, Aneva I, Denev P, et al. Antioxidant activities and phenolic compounds in Bulgarian Fumaria species. Int J Curr Microbiol Appl Sci 2014;3:296-306.

17. Popova V, Tasheva S, Ivanova T, Stoyanova A. Technology for obtaining ethanol extracts from three Nicotiana species based on their tannin content. J Multidiscip Eng Sci Technol 2018;5:9043-8.

18. Regulation (EC) No1223/2009 of the European Parliament and of the Council of 30 November 2009 on Cosmetic Products. OJ L342, 22.12.2009. p. 59-209.

19. Popova V. Obtaining and Analysis of Aromatic Extraction Products for Expanding the Usability of Tobacco (Nicotiana tabacum L.). DSc Dissertation. Plovdiv: UFT; 2015.

20. Popova V. Liquid extracts from tobacco (N. tabacum L.). Sci Works UFT 2014;61:279-83.

21. Popova V, Ivanova T, Stoyanova A, Georgiev V, Hristeva T, Nikolova V, et al. Phytochemicals in leaves and extracts of the variety "Plovdiv 7" of Bulgarian oriental tobacco (Nicotiana tabacum L.). Trends Phytochem Res 2018;2:27-36.

\footnotetext{
How to cite this article:

Popova V, Ivanova T, Stoyanova A, Nikolova V, Hristeva T, Docheva M,

Nikolov N, Iliev I. Polyphenols and triterpenes in leaves and extracts from

three Nicotiana species. J App Biol Biotech. 2019;7(05):45-49.

DOI: $10.7324 / J A B B .2019 .70508$
} 